\title{
Neonates Hearing Screening Results: A Comparison of Chirp and Click Stimuli with an Automated Auditory Brainstem Response Device
}

\author{
Hüseyin Deniz' (D), Alper Yazıcı' (D), Mehmet Enes Coșkun² (1) \\ 'Department of Otorhinolaryngology, Gaziantep University School of Medicine, Gaziantep, Turkey \\ ${ }^{2}$ Department of Pediatrics, Gaziantep University School of Medicine, Gaziantep, Turkey
}

ORCID iDs of the authors: H.D. 0000-000I-5747-7529; A.Y. 0000-000I-7683-8705; M.E.C. 0000-0003-2238-I88X.

Cite this article as: Hüseyin D, Yazıcı A, Coșkun ME. Neonates Hearing Screening Results: A Comparison of Chirp and Click Stimuli with an Automated Auditory Brainstem Response Device. Cyprus J Med Sci 2020; 5(4): 313-6.

\section{BACKGROUND/AIMS}

Automated Auditory Brain Response (AABR) devices are unique tools for neonate hearing screening programs. Contemporary utilization of AABR devices is based on two stimuli called chirp and click. The first study objective was to identify any possible differences in chirp and click stimulus results of the AABR devices in neonates. The second aim was to investigate any possible risk factor that could affect the results of each stimulus.

\section{MATERIAL and METHODS}

Chirp and click stimuli were applied to each neonate using the AABR devices. Results were recorded automatically as pass or failed. Those with failed results were called after month for a retest. Hearing loss risk factors were obtained from the parents and caregivers.

\section{RESULTS}

Twenty-one of the fifty-eight chirp stimuli gave negative results on the AABR in the second AABR test. Twenty-nine of the seventy-six click stimuli on the AABR gave a failed result on retest. The most common risk factors were consanguineous marriage of parents ( $\mathrm{n}=184$ ), history of being admitted to the neonatal intensive care unit $(n=119)$, and jaundice $(n=102)$. In addition, hearing loss was not detected in any neonate and was therefore not considered to significantly affect the results of the chirp or click stimulus on the AABR.

\section{CONCLUSION}

We were unable to prove that the chirp stimulus could be replaced by the click stimuli in neonatal hearing screening using AABR device.

Keywords: Sensorineural, hearing, loss, auditory brain response

\section{INTRODUCTION}

Early detection of hearing loss is essential for the development of social, linguistic and cognitive functions; thus, neonatal hearing screening programs are performed worldwide. An ideal neonatal hearing screening test could detect hearing loss of $\geq 35$ decibels $(\mathrm{dB})$ in the better ear in infants aged $\leq 3 \mathrm{mon}(\mathrm{I})$. Auditory brainstem response (ABR) and otoacoustic emissions (OAE) are the most commonly accepted and performed universal tests (2). Despite being a time-consuming procedure compared to OAEs, some reports have shown that ABRs are more sensitive than otoacoustic emissions $(3,4)$.

Automated auditory brainstem response (AABR) is a useful type of ABR for rapid screening of the hearing ability of newborns. AABR is performed using click or chirp stimuli. A stimulus is a wave that results in a neural activity response. Theoretically, click stimulus starts an earlier neural activity in the broad areas of the basillar membrane than the apical part of the cochlear nerve. This tonotopic activation of the cochlear nerve by click stimulus could cause temporal delays. For preventing these temporal delays, the chirp stimuli were created. Chirp stimuli include both higher and lower frequencies. Theoretically, chirp stimuli stimulates different parts of the cochlear nerve simultaneously (5). The chirp stimulus is superior for the identification of waves or latencies resulting from auditory neural response $(6,7)$. 
It has been hypothesized that chirp stimulus in newborn scans provides faster and safer results than click stimulus in the evalvation of auditory brain responses (8). However, few studies have assessed the clinical application of screening for neonate hearing ability using the chirp versus the click stimuli with an automated ABR device. The main purpose of this article was to identify if there was any significant difference in the neonate hearing screening between the chirp and click stimuli using an AABR device.

\section{MATERIAL and METHODS}

This prospective study includes the results of hearing screening tests performed from November 2018 to February 2019. Hearing screening was performed using Maico Diagnostic MB II Beraphone (Maico Diagnostics, Berlin, Germany ${ }^{\circledR}$ ) (chirp stimuli) and GSI AUDIOscreener (Grason-Stadler, Minnesota, United States ${ }^{\circledR}$ ) (click stimuli) AABR devices with a different kind of stimulus in soundproof rooms. Maico Diagnostic MB I| Beraphone $\left({ }^{\circledR}\right)$ device (CE-Chirp TM) includes a chirp wave with a repetition rate of $93 / \mathrm{s}$ delivered at $35 \mathrm{~dB}$ HL. GSI AUDIOscreener ${ }^{\circledR}$ ) has a click wave $100 \mu$ s width, and a stimulus rate of 3262 per second. The input frequency range of the GSI AUDIOscreener $\left({ }^{\circledR}\right)$ ranges from $30-3000 \mathrm{~Hz}$.

AABR was performed in natural sleep and sedation. Only one kind of stimuli (chirp or click) was applied to each baby. Two groups were created as per the types of stimuli.

The results of each newborn hearing screening were interpreted as "pass" or "fail" automatically by the Maico Diagnostic MB II Beraphone $\left({ }^{\circledR}\right)$ and GSI AUDIOscreener $\left({ }^{\circledR}\right)$ AABR devices. The passing criteria for neonatal hearing screening were defined as the detection of hearing level at $35 \mathrm{~dB} \mathrm{HL}$ at a single device. Those for whom "fail" result was obtained were scheduled for a reevaluation after I mon. As per our hearing policy, if one of the ears did not pass $A A B R$, we accepted the result as a failure and planned further investigation.

Information regarding demographic variables and risk factors was obtained from the parents or caregivers. The risk factors were categorized as follows. Based on the age, the subjects were classified as newborns ( $\leq 28 \mathrm{~d}$ old) and infants ( $>28 \mathrm{~d}$ old). A cut off of $1500 \mathrm{~g}$ was used to classify the subjects as per birth weight. Duration of pregnancy was classified as $>38$ wk or $<38$ wk. Intensive care history was defined by the implementation of mechanical ventilation for at least $5 \mathrm{~d}$.

The following risk factors were estimated: consanguineous marriage of parents, hearing loss event in the family, speech disorder event in the family, history of phototherapy treatment, and drug use by the mother during pregnancy. The effect of these

\section{Main Points:}

- Neonatal hearing screening is crucial for the early detection of hearing loss individuals.

- $\quad A A B R$ is a universal gold standard for detecting hearing loss in neonates.

- Despite the broad usage of chirp stimulus, click stimulus also demonstrates accurate results. risk factors was investigated in those two stimuli groups separately.

Written informed consent was obtained from parents or caregivers of all the patients. Ethical approval was obtained from the University of Gaziantep Ethical Committee (approval number of 2019/116).

\section{Statistical Analysis}

The categorical variables of two independent groups were compared using Chi-Square test. For predicting multiple risk factors, multiple logistic regression models were used. Odds ratios were calculated for each risk factor with a 95\% confidence interval. All Statistical analyses were performed using the Statistical Package for Social Sciences software version 22.0 (IBM SPSS Corp.; Armonk, NY, USA).

\section{RESULTS}

Both the ears of 609 subjects (294 girls and 315 boys) were screened with an AABR device at the University of Gaziantep Audiology department. Three hundred and thirteen of these patients were provided the chirp stimulus and the others were provided the click stimulus. The mean age (day) of the subjects was $23,4 \pm 8,9$ (range I-45); the average age of those in the chirp group was 23,9 9,2 (range 1-45) and that of those in the click group was 22,9 $\pm 7,6$ (range 1-44). The chirp group had 144 men and 152 women; the click group had I5I men and 162 women. The chirp and click stimulus groups did not show any significant difference based on age $(p>0,005)$ or $\operatorname{sex}(p>0,005)$.

Total 134 patients failed in the initial hearing assessment. Fifty-eight of those who failed were screened using the click stimulus, and 76 were screened using the chirp stimulus. Further, 44 of those in the click group failed bilaterally, that is, in both ears. In contrast, 49 subjects in the chirp group failed bilaterally. One month thereafter, the chirp and click stimuli were applied again for the 134 subjects who failed the test. The same stimuli were given to the same subject, and the same stimuli were applied in the first test and the retest. Failed chirp results were found in 21 of the 58 subjects who failed the first test. Twenty-nine of 76 babies failed the AABR control tests with the click stimuli. However, the parents of only I patient have applied to our clinic for clinical ABR after the failure of two AABR tests.

Based on the results of the second hearing screening, the effect of stimulus type (click and chirp) used in AABR on hearing screening was not significant $(p=0,817)$. The risk factors that were evaluated have been shown in Table I and 2 for different stimuli.

The most common risk factors for hearing loss were consanguineous marriage of parents $(n=184)$, followed by history of admission to neonatal intensive care unit (NICU) ( $n=119)$, and jaundice $(n=102)$. One multivariate analysis was performed for the click and chirp groups after multiple binary regression models were created. The risk factors were displayed separately for chirp stimulus in Table I and for click stimulus in Table 2. Multivariate analysis identified that the evaluated risk factors did not significantly influence the results of the ABR to chirp or click stimulus. 


\begin{tabular}{lccccc|} 
TABLE I. Results of the multivariate analysis for chirp stimuli \\
& & & \multicolumn{2}{c}{$95 \% \mathrm{Cl}$ for OR } \\
\cline { 5 - 6 } Variable & $\mathbf{P}$ & OR & Lower & Upper \\
\hline Sex & 0.437 & 1.539 & 0.517 & 4.585 \\
Age (days) & 0.258 & 1.333 & 1.314 & 1.99 \\
Birth weight & 0.18 & 1.618 & 0.07 & 0.922 \\
Consanguineous marriage & 0.612 & 0.741 & 0.232 & 2.367 \\
Family history of hearing loss & 0.278 & 0.946 & 0.876 & 1.022 \\
Family history of speech disorder & 0.18 & 0.919 & 0.835 & 1.011 \\
Pregnancy duration & 0.181 & 1.050 & 0.954 & 1.155 \\
Intensive care history & 0.696 & 0.727 & 0.146 & 3.614 \\
Hyperbilirubinemia with exchange & & & & \\
transfusion & 0.278 & 0.946 & 0.876 & 1.022 \\
Ototoxic Drug Use & 0.447 & 0.973 & 0.922 & 1.027 \\
\hline
\end{tabular}

\begin{tabular}{|lccccc|}
\hline TABLE 2. Results of the multivariate analysis for click stimuli \\
Variable & & \multicolumn{4}{c}{$95 \% \mathrm{Cl}$ for OR } \\
\cline { 5 - 6 } Sex & $\mathbf{p}$ & OR & Lower & Upper \\
Age (days) & 0.082 & 0.39 & 0.149 & 1.018 \\
Birth weight & 0.993 & 0.998 & 0.596 & 1.67 \\
Consanguineous marriage & 0.26 & 1.644 & 1.37 & 1.97 \\
Family history of hearing loss & 0.936 & 1.042 & 0.384 & 2.825 \\
Family history of speech disorder & 0.3 & 0.293 & 0.025 & 3.391 \\
Pregnancy duration & 0.727 & 0.609 & 0.37 & 10.12 \\
Intensive care history & 0.068 & 1.074 & 0.973 & 1.186 \\
Hyperbilirubinemia with exchange & & & & \\
transfusion & 0.134 & 0.327 & 0.072 & 1.489 \\
Ototoxic Drug Use & 0.727 & 0.609 & 0.037 & 10.124 \\
\hline
\end{tabular}

\section{DISCUSSION}

As per our findings, AABR neonatal hearing screening results using the chirp stimuli were not superior to those obtained using the click stimuli.

There was no statistical evidence regarding the type of stimuli as per the results of the hearing screening in neonates. However, there was a marked trend for the use of the chirp stimuli for the screening of neonate hearing.

Both the stimuli were equally effective. Previous research suggests that narrow band chirp stimuli were expressed as a fast and reliable assessment of auditory thresholds as compared to click stimuli $(9,10)$. Moreover, the chirp stimuli provide more evident $\vee$ wave configuration than the click stimuli in the evaluation of the auditory neural pathway $(5,6,11)$. This discrepancy in the findings and previous reports may be related to the automated $A B R$ devices rather than the stimulus type. When compared to diagnostic $A B R$, nearly $40 \%$ of the infants with hearing loss over $45 \mathrm{~dB}$ hearing level passed the test using the AABR device (I2). This finding was believed to be related to non-auditory neural activity or electromagnetic background noise that could be misinterpreted using the AABR device (12).
The most common risk factor for neonate hearing loss in this study was consanguineous marriage of parents; this result was contradictory to that reported by previous studies $(13,14)$ and may be related to social factors in our region. The second common risk factor was a history of NICU admission. MBII BERAphone with chirp stimuli was compared with a standard conventional ABR with click stimuli; the sensitivity was 100\% and specificity was $96.8 \%$ by Melagrana et al. at NICU(ok) (I5). Based on studies with a different design, Gustini et al. and Meier et al. displayed similar results in the comparison of chirp and click stimuli with $\operatorname{AABR}(16,17)$. Consistent with our findings, the aforementioned articles did not absolutely recommend the replacement of one stimulus by another.

The following was a study limitation: low application rates of patients who did not pass the second AABR disallowed further investigation that would enable a comparison of our results with those of diagnostic ABR. The second limitation of this study was that we did not apply two different stimuli in the same neonates. A further study of applying both click and chirp stimulus to the same neonate may enhance the findings of this study.

In conclusion, we believe that the chirp stimulus cannot be replaced by the click stimuli in neonatal hearing screening using an AABR device. Moreover, we could not conclude that a certain type of stimulus had a noticeable effect on hearing screening in newborns with risk factors.

Ethics Committee Approval: Ethics committee approval was received for this study from the ethics committee of Gaziantep University (2019/116)

Informed Consent: Written informed consents were taken from the parents and caregivers of the patients.

Peer-review: Externally peer-reviewed.

Author contributions: Concept - H.D.; Design - H.D., A.Y.; Supervision - A.Y., M.E.C.; Resource - H.D.; Materials - H.D.; Data Collection and/or Processing - H.D.; Analysis and/or Interpretation - A.Y., M.E.C.; Literature Search - A.Y., M.E.C.; Writing - A.Y., M.E.C.; Critical Reviews - A.Y., M.E.C.

Conflict of Interest: Authors have no conflicts of interest to declare.

Financial Disclosure: The authors declared that this study has received no financial support.

\section{REFERENCES}

I. Erenberg A, Lemons J, Sia C, Trunkel D, Ziring P, Adams M, et al Newborn and infant hearing loss: detection and intervention. American Academy of Pediatrics. Task Force on Newborn and Infant Hearing, 1998- 1999. Pediatrics 1999; 103(2): 527-30. [Crossref]

2. Newborn and Infant Hearing Screening CURRENT ISSUES AND GUIDING PRINCIPLES FOR ACTION WHO Library Cataloguing-in-Publication Data Newborn and Infant Hearing Screening: Current Issues and Guiding Principles for Action. https://www. who.int/blindness/publications/Newborn_and_Infant_Hearing_ Screening_Report.pdf. Accessed August 7, 2019.

3. Hahn M, Lamprecht-Dinnesen A, Heinecke A, Hartmann S, Bülbül $S$, Schröder $G$, et al. Hearing screening in healthy newborns: feasibility of different methods with regard to test time. Int $\mathrm{J}$ Pediatr Otorhinolaryngol 1999; 5I(2): 83-9. [Crossref]

4. Iwasaki S, Hayashi Y, Seki A, Nagura M, Hashimato Y, Oshima G, et al. A model of two-stage newborn hearing screening with auto- 
mated auditory brainstem response. Int J Pediatr Otorhinolaryngol 2003; 67(10): 1099-104. [Crossref]

5. Dau T, Wegner O, Mellert $\mathrm{V}$, Kollmeier B. Auditory brainstem responses with optimized chirp signals compensating basilar-membrane dispersion. J Acoust Soc Am 2000; 107(3): 1530-40. [Crossref]

6. Zirn S, Louza J, Reiman V, Wittlinger N, Hempel JM, Schuster M. Comparison between ABR with click and narrow band chirp stimuli in children. Int J Pediatr Otorhinolaryngol 2014; 78(8): 1352-5. [Crossref]

7. Venail F, Artaud JP, Blanchet C, Uziel A, Mondain M. Refining the audiological assessment in children using narrow-band CE-Chirpevoked auditory steady state responses. Int J Audiol 2015; 54(2): 106-13. [Crossref]

8. Cebulla M, Lurz H, Shehata-Dieler W. Evaluation of waveform, latency and amplitude values of chirp ABR in newborns. Int J Pediatr Otorhinolaryngol 2014; 78(4): 63I-6. [Crossref]

9. Elberling $C$, Don M, Cebulla M, Stürzebecher E. Auditory steadystate responses to chirp stimuli based on cochlear traveling wave delay. J Acoust Soc Am 2007; 122(5): 2772. [Crossref]

10. Maloff ES, Hood LJ. A comparison of auditory brain stem responses elicited by click and chirp stimuli in adults with normal hearing and sensory hearing loss. Ear Hear 2014; 35(2): 27l-82. [Crossref]

II. Cebulla M, Hofmann S, Shehata-Dieler W. Sensitivity of ABR based newborn screening with the MBII BERAphone ${ }^{\circledR}$. Int J Pediatr Otorhinolaryngol 2014; 78(5): 756-6I. [Crossref]
12. LevitY, Himmelfarb M, Dollberg S. Sensitivity of the Automated Auditory Brainstem Response in Neonatal Hearing Screening. Pediatrics 2015; 136(3): e64l-e647. [Crossref]

13. Bielecki I, Horbulewicz A, Wolan T. Risk factors associated with hearing loss in infants: An analysis of 5282 referred neonates. Int $\mathrm{J}$ Pediatr Otorhinolaryngol 20ll; 75(7): 925-30. [Crossref]

14. Martínez-Cruz CF, Poblano A, Fernández-Carrocera LA. Risk factors associated with sensorineural hearing loss in infants at the neonatal intensive care unit: 15-year experience at the National Institute of Perinatology (Mexico City). Arch Med Res 2008; 39(7): 686-94. [Crossref]

15. Melagrana A, Casale S, Calevo MG, Tarantino V. MBII BERAphone and Auditory Brainstem Response in newborns at audiologic risk: Comparison of results. Int J Pediatr Otorhinolaryngol 2007; 7I(8): 1175-80. [Crossref]

16. Guastini L, Mora R, Dellepiane M, Santomauro V, Mora M, Rocca A, et al. Evaluation of an automated auditory brainstem response in a multi-stage infant hearing screening. Eur Arch Otorhinolaryngol 2010; 267(8): 1199-205. [Crossref]

17. Meier S, Narabayashi O, Probst R, Schmuziger N. Comparison of currently available devices designed for newborn hearing screening using automated auditory brainstem and/or otoacoustic emission measurements. Int J Pediatr Otorhinolaryngol 2004; 68(7): 92734. [Crossref] 